\title{
Precariedade e revisão da licença ambiental
}

\section{Environmental licence: precarity and review}

\section{Helena Telino Neves}

Professora Universitária. Advogada. Bióloga. Doutoranda e Mestre em Direito pela Faculdade de Direito da Universidade de Lisboa. Av. Dr. Cristiano Guimarães, 1735 Planalto, Belo Horizonte, MG (CEP 31720-300) E-mail: htelino@hotmail.com.

Resumo. A licença ambiental é um instrumento de controle da Administração Pública sobre as atividades poluidoras ou utilizadoras de recursos naturais. A política de proteção ambiental tem buscado acompanhar o desenvolvimento da atividade de maneira contínua, dada a imprevisibilidade do risco ambiental e suas potenciais consequências nefastas. A proposta deste trabalho consiste em avaliar em quais condições o Poder Público poderia rever a licença ambiental antes do término do prazo de validade. No caso da ocorrência de circunstâncias imprevisíveis danosas ao ambiente, o Poder Público deve proceder à revisão da licença ambiental. Neste caso, não se trata de uma mera conveniência da Administração, mas um dever de alterar as condições anteriormente previstas. A possibilidade de revisão deve ficar condicionada à demonstração de alguns fatores pela Administração Pública, nomeadamente da inconveniência na manutenção dos termos originários da licença ambiental, objetivando proteger os titulares da licença de atos arbitrários da Administração. A publicidade e transparência nos processos de revisão coadunamse com as melhores práticas de gestão ambiental e políticas públicas a serem desenvolvidas, atendendo ao princípio do desenvolvimento sustentável, das melhores técnicas disponíveis e da inclusão social na sociedade de risco.

Palavras-chave: Meio ambiente; licença ambiental; revisão; risco ambiental.

Abstract. The Environmental Licence is a Public Administration's instrument of control over the polluting activities or those that use natural resources. The environmental protection policy must follow the development of the activity, given the unpredictability of environmental risk and its potential negative consequences. The purpose of this paper is to assess conditions in which the Public Administration could review the Environmental Licence before the expiration date. In case of unforeseen circumstances harmful to the environment, the Public Administration should revise the Environmental Licence. In this case, it isn't a Public Administration's convenience, but a duty to change the conditions previously planned. The possibility of review should be made conditional to the demonstration of some factors by the Public Administration, including the inconvenience of the original terms of the Environmental Licence, aiming to protect the holders of the arbitrary acts of the Administration. Publicity and transparency in the review are fundamental to guarantee best environmental management practices and policies to be developed, taking into account the principle of sustainable development, the Best Available Techniques and social inclusion in a Risk Society.

Keyword: Environment; environmental licence; review; environmental risk.

\section{Introdução}

O caráter multidisciplinar do Direito do Ambiente é fundamental no processo de avaliação dos impactos gerados por atividades potencialmente poluidoras que
Recebido: 06/10/2014

Aceito: $10 / 10 / 2014$

Publicado: 20/11/2014

Acesso aberto. Artigo completo. 
reais consequências somente serão apuradas após a ocorrência de um dano.

O licenciamento ambiental é o procedimento administrativo que materializa o controle do desenvolvimento das atividades econômicas com interferência no ambiente, buscando regular os efeitos que uma atividade gera, através da imposição de padrões e condicionantes ambientais que devem ser atendidos pelo titular da licença.

Num contexto em que a incerteza mostra-se elemento nuclear e a atuação antecipada é imprescindível, a política de proteção ambiental tem buscado acompanhar o desenvolvimento da atividade de maneira contínua. Houve uma mudança de paradigma, em que a licença ambiental não é mais um instrumento estático limitado à sua emissão.

O objetivo deste trabalho é tratar do licenciamento ambiental e da possibilidade de revisão das licenças ambientais diante de eventos supervenientes e que importem na criação de grave risco ao ambiente, tentando refletir sobre os limites desta revisão.

Em nome da proteção efetiva do ambiente, o órgão ambiental poderia reavaliar os comandos exarados em uma licença em vigência e exigir a adequação às novas diretrizes ambientais, caso existissem, uma vez que a gestão continuada do risco é tarefa imprescindível para a concretização de uma sustentabilidade democrática e participativa.

A discussão proposta não pode ser satisfatoriamente realizada sem que se adiante uma noção geral sobre o risco ambiental e a influência dos princípios da precaução e da prevenção nos procedimentos de análise de risco.

Posteriormente, trataremos do procedimento licenciatório. Aborda-se a controversa natureza jurídica da licença ambiental. Reflete-se sobre a viabilidade de um novo conceito de licença ambiental que atenda às peculiaridades deste instrumento, dada a incerteza dos riscos e o desenvolvimento tecnológico e científico constante. Aprecia-se o tema dos sujeitos ativos e passivos do processo de licenciamento e da listagem das atividades potencialmente poluidoras definidas na legislação.

Após, aborda-se a possibilidade da revisão da licença ambiental no curso de sua vigência. Faz-se uma breve análise da gestão preventiva dos riscos pela Administração Pública. Examina-se a previsão legal da revisão antecipada da licença ambiental nos ordenamentos português e brasileiro. Finalizamos a investigação com uma tentativa de delinear limites à atuação do Poder Público na revisão da licença ambiental, tendo em consideração a influência do princípio da confiança na estabilidade dos atos administrativos.

\section{0 risco ambiental}

O conceito de sociedade de risco foi desenvolvido pelo alemão Urick Beck no livro "A Sociedade do Risco: rumo a uma nova modernidade" (Beck, 2002), salientando a ideia de que os recentes desenvolvimentos ocorridos em nível global, a partir de meados do século passado, romperam com a estrutura da sociedade industrial clássica, afastando-a e fazendo surgir a sociedade industrial do risco.

Durante anos, os processos de desenvolvimento introduziram danos irreversíveis que culminaram em desastres de grandes proporções, especialmente por força da exploração ilimitada dos recursos naturais. Beck (2002) sinalizou para os efeitos negativos da exploração e do desenvolvimento tecnológico, que acabariam por ameaçar a própria coletividade.

A constatação de que a exploração insustentável dos bens traz a possibilidade de desencadeamento de graves desastres fez com que a sociedade reclamasse pela instituição de novas formas de controle, não só do perigo, mas especialmente do risco.

Sublinhe-se que, ao contrário do perigo, que aponta para uma situação direta de potencial lesão e assume o dano como hipótese concreta a ser considerada, o risco identifica a possibilidade abstrata de ocorrência de um gravame, uma probabilidade que admite diferentes graus de estimativa.

Se quisermos procurar o momento inicial em que a gestão de riscos ambientais surge, formalmente, na Europa Comunitária, devemos recuar até 1982, quando foi adotada a Primeira Diretiva visando à prevenção de acidentes industriais graves que envolveram substâncias químicas perigosas. A adoção da Diretiva foi a resposta europeia a um grave acidente industrial de gases tóxicos ocorrido numa indústria na região 
de Seveso, na Itália. A Diretiva foi designada por "Diretiva Seveso" (Aragão, 2010).

Ora, em todos os instrumentos destinados à antecipação de riscos dois princípios imperam: o da prevenção e o da precaução.

\section{A influência dos Princípios da Pre- venção e da Precaução nos procedi- mentos de análise de risco}

A Declaração do Rio de Janeiro sobre Meio Ambiente e Desenvolvimento de 1992 consagrou a precaução no Princípio 15: "Quando houver ameaça de danos sérios ou irreversíveis, a ausência de absoluta certeza científica não deve ser utilizada como razão para postergar medidas eficazes e economicamente viáveis para prevenir a degradação ambiental”.

O princípio da precaução é parâmetro decisório fundamental nos casos em que a avaliação de riscos não conduz a uma resposta unívoca (Estorninho, 2013). Poucos princípios do Direito estão envoltos em tanta polêmica como o princípio da precaução. Polêmicas que passam tanto pela delimitação de sua definição, como pela própria existência autônoma enquanto princípio ${ }^{1}$.

Contudo, o Tribunal de Justiça da União Europeia já reconheceu a autonomia do princípio em vários acórdãos, inclusive justificando com o mesmo a prevalência da proteção ao ambiente, consumidores e saúde pública² ${ }^{2}$.

Se é certo que a precaução é invocada quando a informação científica é inconclusiva e haja indicações de possíveis efeitos nocivos sobre o ambiente, também é evidente que uma medida preventiva não pode ser validamente fundamentada com uma abordagem demasiado hipotética do risco, assente em meras suposições vagas.

Em matéria ambiental, a precaução poderia ser sempre um óbice à autorização de atividades potencialmente poluidoras, uma vez que estamos diante de riscos incertos. A precaução, portanto, deve ser utilizada tendo como recorte o princípio da proporcionalidade.

É em função da proporcionalidade que deve ser feita a opção entre proibir/autorizar condicionar/impor obrigações e também a decisão de acompanhar a evolução científica e rever periodicamente os termos da autorização. Diante das incertezas, os órgãos administrativos e jurisdicionais têm uma grande margem de discricionariedade na tomada de decisões.

Se é certo que os procedimentos autorizativos lidam em regra com riscos certos (no licenciamento de uma fábrica de cimento sabemos que há riscos de poluição do solo e do ar, por exemplo, e diante desses riscos são adotadas medidas contentoras dos danos, de modo a evitá-los - e aqui estamos diante do princípio da prevenção), não se pode afastar a precaução nos procedimentos autorizativos ambientais ${ }^{3}$.

O princípio da precaução ganha força em razão da imprecisão das conclusões científicas, da imprevisibilidade do risco ambiental. Enquanto a prevenção busca combater os perigos concretos, a precaução coloca-se diante dos perigos abstratos pregando a dúvida em favor do ambiente (in dubio pro natura).

O princípio da prevenção postula a adoção de medidas que impeçam a ocorrência de uma ação danosa sobre o meio ambiente, ou seja, atua mediante a antecipação de resultados, prevenindo os possíveis efeitos nocivos, pois os danos são conhecidos.

O que importa é salientar que, refletindo esta ideia de proteção e concretizando o controle de riscos ambientais, emergem os procedimentos de avaliação e gestão do risco. Dentre os instrumentos de gestão de risco destaca-se o licenciamento ambiental, medida que engloba o acompanhamento de atividades potencial ou efetivamente poluentes.

\section{Procedimento licenciatório e licença ambiental}

$\mathrm{O}$ ato administrativo é um ato jurídico unilateral praticado por um órgão de Administração no exercício do poder administrativo e que visa à produção de efeitos jurídicos sobre uma situação individual num caso concreto (Caupers, 2007, p. 188). É uma conduta voluntária de um órgão da Administração que, no exercício de um poder público e para prossecução de interesses postos por lei a seu cargo, produza efeitos num caso concreto ${ }^{4}$.

A licença é o ato administrativo pelo qual um órgão da Administração atribui a alguém o direito de exercer uma atividade 
que é por lei relativamente proibida. As licenças ambientais podem estabelecer medidas de controle ambiental, condicionantes e níveis aceitáveis de emissão de poluentes a serem observados durante a execução da atividade para evitar ou diminuir os danos ambientais causados.

O licenciamento ambiental é um mecanismo estatal que permite o controle das atividades econômicas que geram ou possam gerar impactos ao meio ambiente. Ao particular é negada a possibilidade de emitir poluição proveniente da exploração de determinadas atividades industriais para o ar, água e solo, sem se munir previamente de um ato administrativo conformador dos limites deste desgaste (Gomes, 2008, p. 1053).

A licença ambiental só será expedida quando forem atendidas todas as condições impostas pelo órgão ambiental, condições que incluem maneiras de eliminar, neutralizar ou mitigar os impactos negativos decorrentes da atividade a ser licenciada.

Os atos provisórios e precários verificam-se no domínio do licenciamento ambiental, sobretudo em relação aos problemas colocados pela proteção ambiental e urbanística, levando nomeadamente à emissão de licenças que ficam condicionadas à utilização das melhores técnicas disponíveis (Oliveira, 2010).

\subsection{Sujeito ativo}

Os sujeitos ativos são aquelas entidades intervenientes no procedimento de concessão da licença ambiental.

No Brasil, o Sistema Nacional do Meio Ambiente - SISNAMA é um sistema administrativo de coordenação de políticas públicas de meio ambiente composto por órgãos da União, Estados-Membros, Distrito Federal e Municípios, cujo objetivo é concretizar as diretrizes da Política Nacional do Meio Ambiente. Conforme define a Política Nacional do Meio Ambiente, somente os órgãos do SISNAMA podem licenciar.

Cada ente federado criará e estruturará um órgão executor próprio, responsável por exercer as competências da polícia administrativa, sendo certo que os empreendimentos e atividades são licenciados ou autorizados, ambientalmente, por um único ente federativo, conforme as atribuições estabelecidas nos termos da Lei Complementar ${ }^{\circ} 140 / 2011$.

Em Portugal, a licença ambiental é concedida pela Agência Portuguesa do Ambiente - APA.

\section{ambiental}

\subsection{Natureza jurídica da licença}

Em Portugal, a autorização e a licença são uma espécie do gênero 'atos permissivos', atos que possibilitam a alguém a adoção de uma conduta ou a omissão de um comportamento que de outro modo lhe estariam vedados. Enquanto a autorização se relaciona com direitos ou competências preexistentes, cujo exercício a Administração Pública vem permitir, a licença caracteriza-se pela proibição legalmente estabelecida do exercício de uma atividade privada, proibição essa que vem a ser removida, não sendo o particular titular de qualquer direito face à Administração (Amaral, 2001).

O regime jurídico português do licenciamento ambiental está previsto no Decreto-Lei $\mathrm{n}^{0} 127 / 2013$, de 30 de agosto, que transpôs para o ordenamento interno a Diretiva $n^{\circ}$ 2010/5/UE, do Parlamento Europeu e do Conselho, de 24 de novembro, relativa às Emissões Industriais. Um aspecto relevante refere-se ao âmbito de aplicação do regime jurídico da prevenção e controle integrado da poluição no que toca às alterações substanciais das instalações ${ }^{5}$. Basta que a alteração produza efeitos nocivos e significativos para estar submetida à nova licença ambiental.

A Lei Federal $n^{\circ}$ 6.938/1981, que institui a Política Nacional do Meio Ambiente - PNMA, estabelece que a construção, instalação, ampliação e funcionamento de estabelecimentos e atividades utilizadores de recursos ambientais, efetiva ou potencialmente poluidores ou capazes, sob qualquer forma, de causar degradação ambiental dependerão de prévio licenciamento ambiental (art. 10).

O licenciamento ambiental no Brasil é, portanto, o procedimento administrativo destinado a licenciar atividades ou empreendimentos utilizadores de recursos ambientais, efetiva ou potencialmente poluidores ou capazes de causar degradação ambiental $^{6}$ em qualquer uma das fases: fase 
prévia (onde se analisa a viabilidade de um empreendimento, exigem-se estudos ambientais, realizam-se audiências públicas, terminando com a emissão da Licença Prévia - LP); fase de construção e instalação (procedimento administrativo que analisa a possibilidade de se construir ou instalar um empreendimento e termina com a emissão da Licença de Instalação - LI); fase de funcionamento (procedimento administrativo que objetiva autorizar a operação e funcionamento e termina com a emissão da Licença de Operação - LO). Caso haja quaisquer modificações e ampliações capazes de ensejar alterações significativas do ambiente, há que se solicitar a Licença de Alteração - LA, resultante do procedimento administrativo de análise de viabilidade ambiental da alteração ou ampliação pretendida.

Uma diferença peculiar entre Portugal e Brasil é que, no Brasil, há vários procedimentos distintos de licenciamento, consoante a licença ambiental que se pretende obter. Ademais, por ser um Estado Federado, a competência do licenciamento é comum entre a União, Estados-membros, Municípios e Distrito Federal, segundo estabelece o artigo 23, parágrafo único, da Constituição Brasileira de 1988. Portanto, os trâmites dos procedimentos de licenciamento podem variar conforme a legislação de cada ente federado.

Há divergências doutrinárias sobre a natureza jurídica da licença ambiental no Brasil, tendo em vista a diferença conceitual entre licença administrativa (ato vinculado) e autorização administrativa (ato discricionário).

A licença administrativa é ato vinculado, unilateral, pelo qual a Administração faculta a alguém o exercício de uma atividade, uma vez demonstrado pelo interessado o preenchimento dos requisitos legais exigidos. A licença resulta de um direito subjetivo do interessado, razão pela qual a Administração não pode negá-la quando o requerente satisfaz todos os requisitos legais para sua obtenção e, uma vez expedida, traz a presunção de definitividade (Meirelles, 2003, p. 183). Não se admite revogação posterior e, caso haja, enseja indenização.

A grande questão gira em torno do cumprimento de todas as exigências previstas no processo de licenciamento ambiental, que dariam ao empreendedor, no caso de uma mera licença administrativa comum, o direito de obtê-la.

A autorização é ato discricionário, constitutivo de direitos e admite revogação sem possibilidade de indenização. É ato unilateral pelo qual a Administração, discricionariamente, faculta o exercício de atividade material, tendo, em regra, caráter precário (Mello, 2003, p. 401).

Seria a licença ambiental ato vinculado, pelo qual o órgão público se limita a verificar o cumprimento das normas previamente estabelecidas para o exercício da atividade ou seria ato discricionário, pelo qual o órgão público livremente autoriza ou não uma atividade segundo o juízo que faz sobre sua conveniência ou oportunidade?

Há que refletir acerca de uma possível terceira posição, que foge ao enquadramento forçado entre uma destas duas categorias tradicionais do Direito Administrativo brasileiro, identificando a licença ambiental como uma figura híbrida entre licença e autorização.

A licença ambiental possui natureza jurídica sui generis. Por essa razão, qualquer licenciamento ambiental envolveria, essencialmente, um exame do impacto ambiental potencial causado. O deferimento ou indeferimento da licença deve ser tecnicamente fundamentado e essa fundamentação é a motivação do ato administrativo. Não se trata de ato discricionário, fundado no juízo da conveniência ou oportunidade, mas de ato vinculado às normas legais genéricas estabelecidas na legislação.

No caso das licenças ambientais brasileiras há discricionariedade técnica na definição dos critérios a serem atendidos pelo particular em virtude da necessidade de melhor adequação da atividade às normas ambientais, o que sinaliza sua natureza de autorização.

Entretanto, não se ignora a proteção da confiança e dos interesses particulares, considerados em razão das excepcionais hipóteses de revisão da licença e do direito de uma eventual indenização caso a licença seja cancelada de forma injustificada e desmotivada, o que afasta a precariedade da autorização administrativa.

Caberia ao órgão ambiental analisar os documentos à luz das normas vigentes e da boa técnica, detendo a prerrogativa de 
aprovar ou rejeitar, bem como solicitar complementações e esclarecimentos. $\mathrm{Na}$ hipótese de o empreendimento não atender às medidas mitigadoras e condicionantes solicitadas, não será concedida a licença ambiental. Caso seja concedida, o ato é ilegal.

Não se pode negar a possibilidade de a Administração solicitar a revisão da licença ambiental diante da alteração de circunstâncias substanciais que modifiquem significativamente o ambiente ou em decorrência do surgimento de melhores técnicas disponíveis. Não há que se falar em direito adquirido a exercer a atividade poluente, mesmo com a licença ambiental obtida, o que afastaria a sua natureza de mera licença administrativa ${ }^{7}$.

Após obtida a licença ambiental, há uma certa discricionariedade da Administração no processo de acompanhamento da atividade. Na verdade, trata-se de um poder-dever de fiscalização a posteriori. Mas essa discricionariedade é mitigada em função da segurança jurídica e do princípio da confiança. O titular da licença ambiental não pode exercer a sua atividade temendo que, a qualquer tempo e de forma injustificada, a sua licença seja cancelada, revista ou suspensa.

Todavia, a possibilidade de revisão e atualização dos termos de uma licença ambiental em vigência deve existir e deriva do interesse maior de tutela efetiva do ambiente enquanto corolário de um direito fundamental. Trata-se de um procedimento dinâmico e continuado, que permite o prosseguimento da exploração de uma atividade econômica já licenciada sem implicar danos ambientais (Milaré, 2009, p. 438).

\subsection{Sujeito passivo e listagem de atividades potencialmente poluidoras}

São considerados sujeitos passivos do licenciamento ambiental todas as pessoas físicas ou jurídicas, de direito público ou privado, que pretendam ou venham a desenvolver empreendimentos ou atividades potencialmente poluidoras ou utilizadoras de recursos naturais.

É importante salientar que as normas ambientais portuguesas e brasileiras trazem uma listagem de atividades passíveis de licenciamento ${ }^{8}$. Ocorre que o rol definido é meramente exemplificativo, ou seja: a lista de atividades ou empreendimentos sujeitos ao licenciamento ambiental não se resume aos anexos dessas normas legais.

A listagem não é taxativa, em razão da impossibilidade de elaboração de uma relação contendo todas as atividades que deverão se sujeitar ao processo de licenciamento ambiental. Ora, o legislador não é capaz de prever, por ocasião da elaboração da norma legal, todas as situações potencialmente poluidoras - presentes e futuras que serão abarcadas pelo ato normativo.

Com o avanço tecnológico e a consequente mutação dos costumes da sociedade, diversas condutas lesivas ao meio ambiente podem surgir e não serem abarcadas pelas normas ora em vigência. Se acatássemos a teoria de que o rol das normas é taxativo, diversas atividades potencialmente poluidoras e impactantes ao meio ambiente estariam dispensadas do licenciamento ambiental. Deste modo, mesmo que não esteja presente na lista, determinada atividade pode ser compelida a licenciar-se ambientalmente. No caso brasileiro, é o que podemos extrair do art. $2^{\circ}, \S 2^{\circ}$, da Resolução CONAMA n ${ }^{\circ}$ 237/1997\%.

Não há que se questionar sobre uma possível afronta ao princípio da legalidade quando se exige o licenciamento de uma atividade ausente da lista das atividades ou empreendimentos prevista na legislação. Por se tratar de um direito difuso, pode o órgão competente exigir o licenciamento, mesmo que a atividade não esteja presente no rol de atividades ou empreendimentos passíveis de licenciamento ambiental.

Obviamente, isso não dá margem para que o Poder Público atue de forma arbitrária. A exigência de submissão ao licenciamento ambiental de determinada atividade não listada ${ }^{10}$ deve ser proporcional, a fim de que não se imponha ao administrado uma exigência desnecessária e infundada. Esta exigência deve basear-se em critérios técnicos que justifiquem o fato de a atividade ser potencialmente poluidora. Ressalta-se que, neste caso, não se trata de conveniência ou oportunidade da Administração Pública, mas de certa dose deliberativa justificável pelo interesse coletivo de um meio ambiente equilibrado e saudável. 


\section{Revisão das licenças ambientais no curso de sua vigência}

Se é certo que os bens ambientais devem ser conservados per si, também é certo que, numa perspectiva antropocêntrica alargada, não se pode pretender uma ausência total de intervenções humanas no ambiente. A licença ambiental, ato administrativo que autoriza uma atividade econômica potencial ou efetivamente poluidora estabelecendo prazo e condicionantes que deverão ser observadas pelo operador ao longo da sua vigência, viabiliza a exploração sustentada da atividade.

A contínua atualização dos parâmetros que conformam a exploração pelo titular da licença faz-se necessária num contexto influenciado por alterações tecnológicas e científicas e pelas incertezas inerentes ao risco, em nome da eficiência ambiental destas atividades. Esta atualização é concretizada por meio da revisão da licença ambiental, antes mesmo do seu termo final, modificando as suas condicionantes.

\section{dos riscos \\ 4.1 Controle e gestão preventiva}

O risco no Direito do Ambiente é diverso do risco contratual, risco normal do negócio no âmbito do Direito Privado. Ao tratarmos de gestão de risco ambiental, estamos tratando de gestão do imprevisível, do incerto, mas que, dada a sensibilidade e irreparabilidade do bem ambiental, não pode ser subestimado. Uma vez emitida a licença, em correspondência ao dever de tutela dos recursos naturais, cabe ao Estado, por intermédio dos órgãos ambientais, fiscalizar e monitorar as atividades licenciadas e os riscos que podem surgir.

A revisão das licenças no decorrer da validade (surgimento de novos riscos, melhorias técnicas, necessidade de adaptação permanente) retira alguma estabilidade do ato autorizativo, mas é justificável. Em casos extremos e, em prol do interesse público, pode chegar-se até à revogação do ato $^{11}$.

É possível a atualização das condicionantes das licenças ambientais, afastando-se o emprego de um controle ambiental ultrapassado, e conferindo ao operador um tempo hábil de recuperação dos investimentos relacionados às adaptações implementa- das por força das imposições do licenciamento.

Sustentar a imutabilidade da licença ambiental e a continuidade da exploração de uma atividade que esteja causando danos é o mesmo que conferir ao empreendedor um cheque em branco, permitindo-lhe que, com base em licença pretérita, possa causar toda e qualquer degradação ambiental (Milaré, 2009, p. 427).

\subsection{Previsão legal}

A alteração de circunstâncias que estavam na base de conformação do ato licenciador, a ocorrência de fatores extraordinários, a instabilidade gerada pelo risco e o desenvolvimento tecnológico justificam modificações da licença no curso de sua vigência $^{12}$. Impedir o reexame das condições em que a atividade é desenvolvida resultaria na admissão da continuidade, sob a chancela de uma autorização, do exercício de uma atividade lesiva a um bem jurídico protegido, numa aceitação da prática de poluição autorizada, ou melhor, licenciada (Canotilho, 1993, p. 47).

No Brasil, a possibilidade de revisão da licença ambiental está prevista na Lei Federal n ${ }^{0}$ 6.938/1981, que estabelece o licenciamento ambiental e a revisão de atividades efetiva ou potencialmente poluidoras como um dos instrumentos da Política Nacional do Meio Ambiente ${ }^{13}$.

Não existe no ordenamento brasileiro uma descrição detalhada das hipóteses legais em que há cabimento da revisão da licença ambiental.

Admite-se a revisão antes do término da validade, mas não há especificações das hipóteses em que tal pode ocorrer. A determinação de um prazo de validade da licença não constitui um direito adquirido em exercer a atividade de forma absoluta.

Desde modo, o órgão ambiental competente, mediante decisão motivada, poderá modificar as condicionantes e as medidas de controle e adequação, suspender ou cancelar uma licença expedida, quando ocorrer a superveniência de graves riscos ambientais e de saúde ${ }^{14}$.

Em Portugal, há a possibilidade de a Agência Portuguesa do Ambiente requerer a atualização da licença ambiental sempre que ocorram alterações significativas das melhores técnicas disponíveis ${ }^{15}$; por 
decisão fundamentada da APA, que imponha ao operador a adoção das medidas adequadas para minimizar ou compensar os efeitos negativos não previsíveis para o ambiente ou para a saúde pública ocorridos durante a exploração da instalação ${ }^{16}$; quando houver alterações substanciais de instalações existentes ${ }^{17}$.

A previsão legal de revisão da licença ambiental previne o titular sobre uma possibilidade de readequação dos termos do ato antes do seu vencimento, fundamentada na atuação preventiva dos riscos, mitigando o princípio da proteção da confiança ${ }^{18}$. É recomendável previsão legal, mas entendemos que a revisão pode ser fundamentada também nos princípios orientadores do Direito do Ambiente.

Não apenas os fatores de ordem normativa servem de fundamento à revisão da licença ambiental. A revisão também poderá ocorrer por força da atuação discricionária do órgão ambiental, em virtude da alteração dos riscos ou surgimento de melhores técnicas disponíveis - MTD, questões que fazem com que o órgão ambiental reflita sobre o mérito da manutenção do ato autorizativo ambiental.

Há bens jurídicos, como o ambiente, que justificam a revisão modificativa dos termos da licença, pautada na preponderância do interesse público sobre o privado, flexibilizando a estabilidade a licença ambiental.

\subsection{Estabilidade dos atos adminis- trativos: proteção da confiança}

Ao princípio de estabilidade da relação jurídica autorizativa, o Direito do Ambiente vem contrapondo um princípio de revisibilidade, diretamente filiado na necessidade de gerir a incerteza associada à técnica (Gomes, 2008, p. 1072).

A revisão da licença ambiental objetiva a modificação ou extinção da autorização conferida em razão da alteração dos pressupostos técnicos e de fato que sobre ela incidiu no momento posterior à concessão e antes do término de seu prazo de validade $^{19}$. Ressalta-se que a revisão de uma licença ambiental não significa a extinção do ato, uma vez que poderá ser somente uma adaptação das condicionantes.

Há quem defenda que o reexame da licença ambiental não seria possível por constituir em modificação unilateral pelo Poder Público, praticada sem o consentimento do particular e com a imposição de uma readaptação antecipada da atividade a condições mais exigentes em razão de regulamentações supervenientes (Mateo, 1991, p. 113).

A revisão da licença ambiental faz surgir um embate entre, de um lado, a estabilidade e a proteção da confiança dos particulares e, do outro, a adequada realização do interesse público.

Estamos diante, portanto, do problema da regra da estabilidade dos atos administrativos e da infrigência do princípio da confiança.

Se é certo que a revisão antecipada da licença ambiental frusta as expectativas da execução das atividades dentro dos padrões estabelecidos, obrigando o titular da licença a promover adaptações, muitas vezes acompanhada de custos não previstos, também é evidente a inexistência de um direito adquirido a poluir.

Não há que se falar em direito adquirido, mesmo quando haja uma licença ambiental que autorize a atividade. A natureza jurídica sui generis da licença ambiental, com determinação de prazo de validade e certa discricionariedade na definição das condicionantes não confere ao titular uma situação definitiva de exploração da atividade.

O órgão ambiental pode alterar ou mesmo cancelar a licença ambiental diante da constatação de que a atividade licenciada esteja causando danos ambientais. É inequívoca, portanto, a ideia de mutabilidade dos termos da licença ambiental, mutabilidade que se contrapõe ao conceito de direito adquirido. $\mathrm{O}$ dever de controle constante da Administração persiste mesmo durante a vigência da licença (Gomes, 2005, p. 42).

4.4 Delineamentos para imposição de limites à atuação do poder público na revisão da licença ambiental

Os órgãos administrativos detêm a prerrogativa de modificar e extinguir os efeitos dos atos que praticam quando entenderem que estes não são mais convenientes e oportunos (Amaral, 2003, p. 435), mas a atuação não deve ser irrestrita, em nome da estabilidade - estabilidade relativa, diga- 
mos, mas não deixa de ser estabilidade dos interesses dos administrados.

$\mathrm{O}$ desenvolvimento de atividades potencialmente poluidoras pressupõe 0 equilíbrio da relação entre o titular da atividade poluente e o Poder Público. O Estado não pode desconsiderar o investimento e todos os atos já praticados pelo administrado, sob pena de impossibilitar o desenvolvimento econômico, contrariando o princípio do desenvolvimento sustentável.

Porém, em nome dos outros princípios norteadores do Direito do Ambiente e considerando o constante avanço tecnológico, não se deve manter a exploração de uma atividade que era sustentável quando da emissão da licença ambiental, mas que, após algum tempo, não pode subsistir do ponto de vista ambiental.

Os critérios de avaliação dos riscos se alteram, bem como a forma de exploração das atividades, o que pode constituir em fator de mutabilidade dos termos que embasaram a concessão da licença, surgindo a necessidade de alterá-la (Pardo, 1999, p. 40).

Resta-nos refletir como conciliar a possibilidade de revisão com as garantias do particular estabelecidas na licença concedida. Isso é importante, pois não se objetiva travar o desenvolvimento econômico.

Na revisão, o titular da licença fica refém da Administração Pública, uma vez que é compelido a obedecer às novas condicionantes e fazer as adaptações exigidas, sob pena de ter suspensa ou cancelada sua atividade. Apesar de a revisão não se consubstanciar numa revogação do ato administrativo, esta promove uma reapreciação negativa pelo menos no que toca às novas exigências impostas ao empreendedor, em regra, exigências mais rigorosas ${ }^{20}$.

A proteção da estabilidade dos atos administrativos, através do segurança jurídica e da proteção da confiança, pode impor limites à atuação do poder público na revisão da licença ambiental. Resta-nos tentar delinear possíveis limites à atuação do poder público nesse processo de revisão.

Em primeiro lugar, a validade da revisão deve ficar condicionada à demonstração da inconveniência e inoportunidade da manutenção dos termos originais da licença, inclusive reconhecendo-se a possi- bilidade de indenização por danos excessivos que possam recair sobre o titular.

A ausência desta demonstração enseja arbitrariedade da Administração Pública, que não deve subsistir. A estabilidade do ato administrativo deve prevalecer quando os particulares e terceiros afetados hajam confiado na perduração dos direitos constituídos, na estrita medida dessa confiança, e enquanto esta for digna de proteção (Calvão, 2005, p. 41).

Em segundo lugar, a possibilidade de revisão está vinculada à proteção do ambiente. Se for realizada pretendendo atender a um interesse público diverso será ilegal, por desvio de poder, suscitando a responsabilidade da Administração por atos ilícitos.

Em terceiro lugar, a tomada de decisão pelo órgão ambiental deve ser proporcional e não deve impor obrigações ou restrições em medida superior àquela estritamente necessária ao atendimento do interesse público, segundo critério de razoável adequação dos meios aos fins (Medauar, 2008, p. 129).

Pensamos aqui, sobretudo, nos custos desta revisão, que implica em gastos não previstos pelo titular da licença.

Em princípio, com a revisão, os operadores arcariam com os custos para a adaptação de suas atividades de acordo com novos parâmetros estabelecidos, uma vez que, não obedecidas às novas exigências, a licença poderá ser revogada e as atividades cessadas. O titular é o maior interessado na manutenção da sua atividade, mas também lhe importa a viabilidade econômica dessa operação, que passa por uma programação dos gastos e estimativas de lucros.

$\mathrm{O}$ interesse ambiental, justificador da revisão, é um interesse difuso. Ao fim e ao cabo, a revisão busca zelar pela qualidade de vida de todos. Entretanto, para além da defesa ambiental, também há um interesse público na manutenção da atividade econômica. Assim sendo, é possível pensarmos num eventual incentivo ou subsídio estatal no caso de revisões impostas pelo órgão ambiental. Impor adaptações que comprometem a continuidade da exploração da atividade é inimaginável.

No entanto, a regra é que o titular da licença arque com os custos da revisão. Um eventual subsídio estatal somente acon- 
teceria no caso da revisão antes do término do prazo de validade da licença onde o titular experimentasse encargos excessivos que comprometessem a continuidade da atividade. Nesse caso, os encargos devem ser divididos entre operador e órgão ambiental, ficando o órgão ambiental com o custeio integral dos gastos que ultrapassem o liame da normalidade, em respeito ao princípio da justa repartição dos encargos públicos. $\mathrm{O}$ operador deverá adaptar as instalações, mas recebendo um subsídio estatal, em relação aos custos excessivos, por conta da divisão dos encargos públicos ${ }^{21}$.

A licença ambiental produz efeitos em relação ao Poder Público, em relação ao particular que dele beneficie e em relação a um eventual terceiro lesado por uma atividade autorizada ao particular. Mas esse ato administrativo emitido de forma lícita não gera um efeito legalizador pleno que faz com que o particular se furte de quaisquer indenizações. A ilicitude de uma eventual lesão não é neutralizada pelo ato administrativo licenciador, nem preclui as ações de defesa de terceiros. Canotilho ensina que trata-se de uma responsabilidade por atos lícitos a cargo de entidades privadas. $\mathrm{O}$ efeito justificativo explica a licitude, mas não justifica a negação do ressarcimento pelo titular da licença ${ }^{22}$.

\section{Considerações finais}

Em sede de interesses ambientais difusos, deve ser sopesada a indeterminação de seus titulares e sua indisponibilidade, além de considerados os seguintes aspectos: sua essencialidade; sua indisponibilidade intrínseca; a equidade intergeracional e o respeito aos princípios do desenvolvimento sustentável, no sentido de compatibilização da defesa dos bens ambientais com o crescimento econômico.

Os bens ambientais são bens difusos, cujo uso é limitado pela obrigação de assegurar às gerações futuras o seu desfrute nas mesmas condições que ocorrem no presente. Deve haver a utilização racional dos recursos ambientais, conservando sua capacidade regenerativa, de forma a garantir a estabilidade ecológica. Diante disso, a legislação estabeleceu mecanismos de salvaguarda do exercício das atividades polui- doras, por intermédio do procedimento de licenciamento ambiental.

As licenças ambientais assumem um papel relevante, já que não mais se limitam a determinar formas de atuação apenas quando da sua emissão, mas também por permitirem o acompanhamento da atividade e a atuação antecipada a situações que ameacem o equilíbrio ambiental, por intermédio do monitoramento permanente do desenvolvimento das atividades pelo Poder Público.

Esse monitoramento constante ligase à instabilidade do risco ambiental. $\mathrm{O}$ risco ambiental é sui generis, porque imprevisível. Uma determinada atividade licenciada hoje, pode futuramente provocar danos que eram inimagináveis na altura da emissão da licença autorizadora da atividade.

As licenças ambientais não constituem atos individuais intangíveis, sendo plenamente possível modificar uma licença emitida, bem como exigir o licenciamento de instalações existentes que não estejam licenciadas (Prieur, 2004, p. 152).

Por sua vez, a listagem de atividades potencialmente poluidoras, cujo licenciamento é obrigatório é meramente exemplificativa, já que o legislador não é capaz de prever todos as atividades degradadoras do ambiente. O Estado pode solicitar o licenciamento de uma atividade que não esteja listada, baseando-se em critérios técnicos que justifiquem esta exigência, como o aparecimento de novos riscos, melhores técnicas disponíveis ou uma necessidade de adaptação da atividade.

Há a possibilidade da previsão de revisão antecipada dos termos da licença ambiental em decorrência do dinamismo em que se insere o controle de atividades potencial ou efetivamente poluentes e da própria natureza jurídica da licença, uma vez que não há presunção de definitividade, como nos casos das licenças administrativas. Todavia, a licença ambiental também não é um ato precário, como a autorização administrativa.

A possibilidade abstrata e imprevisível da ocorrência de um gravame faz com que os proncípios da prevenção e precaução influenciem nos procedimentos de análise de risco, sendo possível rever antecipadamente os termos da licença ambiental. Sus- 
tentar a imutabilidade da licença ambiental durante a sua vigência é conferir um direito adquirido a poluir, que não existe em sede ambiental.

É recomendável a existência de norma legal que preveja a possibilidade de revisão da licença ambiental no curso de sua vigência mas, caso não haja, a revisão pode ocorrer, fundamentada nos princípios gerais do Direito do Ambiente e em decisões motivadas da Administração Pública.

Entretanto, é preciso atentar ao fato de que esta modificação antecipada envolve interesses conflitantes: a proteção do ambiente e a defesa dos interesses do titular da licença, dentre eles a confiança e a expectativa de exercer a atividade conforme as determinantes da licença ambiental emitida.

Impõe-se à Administração a observância de limites à sua atuação com vistas a impedir que a utilização da revisão se dê de maneira irrestrita e abusiva. A decisão do órgão ambiental em rever os termos da licença deve mostrar-se ponderada e razoável em relação aos meios utilizados e aos fins a serem alcançados, diante das condicionantes e dos fatores de risco incidentes no caso, sem imputar sacrifícios desnecessários aos particulares.

A revisão deve ser condicionada à demonstração de inconveniência da manutenção dos termos originais da licença em relação à proteção ambiental. No caso de revisão da licença ambiental e, se recair ao particular custos desproporcionais que inviabilizem a atividade econômica, impõem-se a divisão dos encargos entre o titular da licença e o órgão ambiental, uma vez que a continuidade da atividade também importa ao Estado sob o ponto de vista do desenvolvimento econômico.

\section{Referências}

Amaral, D. F. Curso de Direito Administrativo. Coimbra: Almedina, 2003. v. 2.

Andrade, J. C. V. A revisão dos actos administrativos no Direito Português. Legislação: Cadernos de Ciência de Legislação, Lisboa, n. 9-10, p. 185-202, 1994.

Antunes, T. $\mathbf{O}$ ambiente entre o direito e a técnica. Lisboa: AAFDL, 2003.

Aragão, M. A. S. Dimensões Europeias do Princípio da Precaução. Revista da FDUP, Porto, a. 7, p. 245-291, 2010.
Aragão, M. A. S. O Princípio do Nível Elevado de Proteç̧ão e a Renovação Ecológica do Direito do Ambiente e dos Resíduos. Coimbra: Almedina, 2006.

Beck, U. La sociedad del riesgo. Hacia una nueva modernidad. Barcelona: Paidós, 2002. Disponível em: <http://www.mediafire.com/ download/hiynz5enazz/la_sociedad_del_riesgo. pdf $>$. Acesso em 30 jun. 2013.

Calvão, F. U. Licenciamento Ambiental. In: Cebola, C. M.; Mendes, J. B.; Ferrão, M. C.; Almeida, S. (Coord.). Direito do urbanismo e do ambiente: estudos compilados. Lisboa: Quid Juris, 2010. p. 364-377.

Calvão, F. U. Revogação dos actos administrativos no contexto da reforma do Código de Procedimento Administrativo. Justiça Administrativa, n. 54, p. 33-43, 2005.

Canotilho, J. J. G. Actos autorizativos jurídicopúblicos e responsabilidade por danos ambientais. Boletim da Faculdade de Direito de Coimbra, v. 69, p. 1-69, 1993.

Caupers, J. Introdução ao Direito Administrativo. 9 ed. Lisboa: Âncora, 2007.

Estorninho, M. J. Direito da Alimentação. Lisboa: AAFDL, 2013.

Gomes, C. A. Dar o duvidoso pelo (in)certo? Reflexões sobre o "princípio da precaução”. In: Textos Dispersos sobre Direito do Ambiente. Lisboa: AAFDL, 2005. v. 1. p. 141-174.

Gomes, C. A. Mudam-se os tempos, mudam-se os actos administrativos... Contributo para a construção de um regime de modificação do acto administrativo por alteração superveniente dos pressupostos. In: Estudos em homenagem ao Professor Doutor Marcello Caetano no centenário de seu nascimento. Coimbra: Coimbra Editora, 2006. v. 1. p. 237-266.

Gomes, C. A. O procedimento de licenciamento ambiental revisitado. O Direito, Coimbra, a. 5, p. 1053- 1085, 2008.

Gomes, C. A. Risco e Modificação do Acto Autorizativo Concretizador de Deveres de Protecção do Ambiente. Coimbra: Coimbra Editora, 2007.

Gomes, C. A. Subsídios para um quadro principidológico dos procedimentos de avaliação e gestão do risco ambiental. Textos Dispersos de Direito do Ambiente. Lisboa: AAFDL, 2005. v. 1. p.35-56.

Marques, F. P. A revogação de acto administrativo multipolar. Direito \& Política, Loures, n. 1, p. 46-60, 2012.

Mateo, R. M. Tratado de Derecho Ambiental. Madrid: Trivium, 1991. v. 1.

Medauar, O. Direito Administrativo Moderno. 12. ed. São Paulo: RT, 2008. 
Meirelles, H. L. Direito Administrativo Brasileiro. 28. ed. São Paulo: Malheiros Editores, 2003.

Mello, C. A. B. Curso de Direito Administrativo. 15. ed. São Paulo: Malheiros, 2003.

Milaré, É. Direito do Ambiente: a gestão ambiental em foco: doutrina, jurisprudência, glossário. 6. ed. São Paulo: RT, 2009.

Oliveira, F. P. As mais recentes alterações ao regime jurídico da urbanificação e edificação: breves reflexões sobre o Decreto-Lei $\mathrm{n}^{\circ}$ 26/2010, de 30 de março. Direito Regional e Local, Braga, n. 10, p. 3-14, 2010.

Pardo, J. E. La adaptación de las licencias a la mejor tecnologia disponible. Revista de Administración Pública, Madri, n. 149, p. 37-61, 1999.

Prieur, M. Droit de l'environnement. 5. ed. Paris: Dalloz, 2004.

Silva, D. A. A alteração superveniente da licença ambiental e a superação da estabilidade dos atos ampliativos. In: Gomes, C. A. (Coord.). Por uma nova ordem ambiental internacional: celebrando os 40 anos da Declaração de Estocolmo. Curitiba: Juruá, 2003. p. 67-90.

Sousa, M. R. O acto administrativo no ensino de Marcello Caetano. In: Estudos em homenagem ao Professor Doutor Marcello Caetano no centenário do seu nascimento. Coimbra: Coimbra Editora, 2006. v. 2. p. 177-190.

Talamini, D. C. Revogação do Ato Administrativo. São Paulo: Malheiros, 2002.

Virga, P. Il Provvedimento Amministrativo. 4. ed. Milão: Giuffrè, 1972.

\section{Notas}

${ }^{1}$ Negando a existência do princípio da precaução: Gomes (2005).

${ }^{2}$ Cita-se, a propósito, passagem de um dos acórdãos: "o princípio da precaução pode ser definido como um princípio geral do direito comunitário que impõe às autoridades competentes que tomem medidas adequadas para evitar certos riscos potenciais para a saúde pública, $a$ segurança e o ambiente, dando prevalência aos imperativos ligados à proteção destes interesses sobre os interesses econômicos." Acórdão do Tribunal de Primeira Instância de 26 de novembro de 2002, Artegodan GmbH e outros contra a Comissão das Comunidades Europeias. Disponível em: <http://eur-lex.europa.eu>. Acesso em: 02 de junho de 2013.

${ }^{3}$ No caso dos procedimentos autorizativos para plantio de organismos geneticamente modificados - OGM's, os riscos ambientais no caso de fuga de sementes são imprevistos (haverá con- taminação cruzada entre espécies? Competição com plantas nativas? Geração de pragas resistentes? Interrupção da reciclagem de nutrientes?). A avaliação de riscos ambientais de plantas transgênicas não é conclusiva, mas diante das hipóteses não se deve obstar a adoção de medidas acauteladoras. Aqui, estamos diante da influência do princípio da precaução nos procedimentos de licenciamento.

${ }^{4} \mathrm{O}$ conceito de ato administrativo não é tão simples como parece. Até mesmo para os estudiosos do Direito Administrativo, como o Professor Marcello Caetano, o conceito não foi estanque, sendo modificado no decorrer de sua carreira. Sobre a evolução do ensino do ato administrativo por Marcello Caetano, ver: Sousa (2006).

${ }^{5}$ A Diretiva no 2010/75/UE conceitua alteração substancial como uma modificação da natureza ou do funcionamento, ou uma ampliação, de uma instalação ou de uma instalação de combustão, de uma instalação de incineração de resíduos ou de uma instalação de coincineração de resíduos que possa ter efeitos nocivos significativos na saúde humana ou no ambiente.

${ }^{6}$ Conceito estabelecido no art. $2^{\text {o }}$, I, da Lei Complementar $n^{0} 140 / 2011$, lei brasileira que estabelece a cooperação entre a União, os Estados, o Distrito Federal e os Municípios nas ações administrativas decorrentes do exercício da competência comum relativas à proteção ambiental.

${ }^{7}$ A licença administrativa no Direito Brasileiro tem um caráter de definitividade. Uma vez concedida, ela só poderá ser anulada, modificada ou revogada se comprovada a ilegalidade em sua expedição, o descumprimento pelo particular das condições impostas ou se advier interesse público incompatível com o ato concedido. Emitida a licença, esta tende a se eternizar no tempo. A mera alteração de circunstâncias não justificaria sua revisão. Somente algum vício comprovado na sua expedição e execução ou um verdadeiro interesse público conflitante são fatos idôneos para coibir a atividade licenciada.

${ }^{8}$ No caso da legislação brasileira, as atividades passíveis de licenciamento estão na Resolução CONAMA n 237/1997 e nas normas estaduais e municipais pertinentes, já que a competência para licenciar é comum entre os entes federados, conforme já dito. Em Portugal, a listagem das atividades licenciáveis estão no Anexo I, do Decreto-Lei $n^{\circ}$ 127/2013, de 30 de agosto.

9 “Art. $2^{\circ}$ (...) \& $2^{\circ}$ Caberá ao órgão ambiental competente definir os critérios de exigibilidade, o detalhamento e a complementação do Anexo 1, levando em consideração as especificidades, os riscos ambientais, o porte e outras características do empreendimento ou atividade”. 
${ }^{10}$ As interferências na esfera de liberdade das pessoas, consubstanciada na exigência de licença/autorização, no Brasil, encontra-se embasamento legal no artigo $2^{\circ}$, $\S 2^{\circ}$, da Resolução CONAMA ${ }^{\circ}$ 237/1997.

${ }^{11} \mathrm{~A}$ revogação de atos administrativos tem sido marcada pela contraposição direitos dos cidadãos e interesse público. Ignora-se o tema da revogação de atos administrativos quando estes se referem a interesses conflituantes de diversos particulares. Sobre a revogação dos atos administrativos multipolares: Marques (2012).

${ }^{12}$ Tiago Antunes defende uma contínua adaptação da relação autorizativa ambiental em função da evolução científica e tecnológica. Antunes (2003).

${ }^{13}$ Art. 9 ${ }^{\circ}$, IV, da Lei Federal $n^{\circ}$ 6.938/1981.

${ }^{14}$ Art. 19, III, da Resolução CONAMA no 237/1997.

${ }^{15}$ Art. $78^{\circ}$, do Decreto-Lei no $127 / 2013$.

${ }^{16}$ Art. $19^{\circ}$, no 9, a, do Decreto-Lei n ${ }^{\circ} 127 / 2013$.

${ }^{17}$ Art. $19^{\circ}, n^{\circ} 8$, do Decreto-Lei no $127 / 2013$.
${ }^{18}$ Silva, D. A. A alteração superveniente da licença ambiental e a superação da estabilidade dos atos ampliativos. In: GOMES, C. A. (Coord.). Por uma nova ordem ambiental internacional: celebrando os 40 anos da Declaração de Estocolmo. Curitiba: Juruá, 2003, p. 84.

${ }^{19}$ Gomes, C. A. Mudam-se os tempos, mudam-se os actos administrativos... Contributo para a construção de um regime de modificação do acto administrativo por alteração superveniente dos pressupostos. In: Estudos em homenagem ao Professor Doutor Marcello Caetano no centenário de seu nascimento, v. I. Coimbra: Coimbra Editora, 2006, p. 255.

${ }^{20}$ Sobre o tema: Andrade (1994).

${ }^{21} \mathrm{O}$ subsídio refere-se apenas às despesas que o titular tem com as atividades a fim de executar o ato autorizativo e fruir do mesmo; não se trata de indenização pela extinção antecipada da licença, pelo que resta excluída a indenização por lucros cessantes, por exemplo. Nesse sentido: Talamini (2002) e Virga (1972, p. 466).

${ }^{22}$ Sobre o assunto: Canotilho (1993). 